\title{
Potentials of neuron-specific enolase as a biomarker for gastric cancer
}

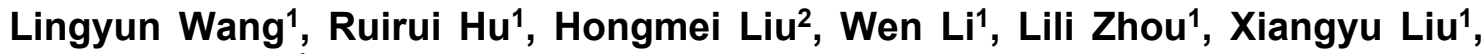 \\ Yuanyuan Ding ${ }^{1 *}$ \\ ${ }^{1}$ Department of Gastroenterology, ${ }^{2}$ Department of Nursing, Jining First People's Hospital of Shandong Province, Shandong \\ 272100, China \\ *For correspondence: Email: DenaeDerrierile@yahoo.com; Tel: +86 5372253431
}

\begin{abstract}
Purpose: To investigate the potentials of neuron-specific enolase (NSE) as a biomarker for gastric cancer (GC).

Methods: Gastric cancer (GC) patients $(n=412)$ who underwent gastrectomy were recruited over a 3year period for this study. Their clinicopathological data such as age, sex, histological type, depth, tumor invasion, lymph node metastasis, and distant metastasis were analyzed. The patients were followed up for four years and the outcomes were also assessed. Histological changes in biopsies and levels of expression of NSE in biopsies and serum of patients were determined using immunohistochemical staining, western blotting and enzyme-linked immunosorbent assay (ELISA), respectively.

Results: Immunohistochemical staining showed that NSE was differentially expressed in the cytoplasm of GC cells. Histological changes in biopsies of patients in the overexpression group were not significantly different from those of patients in under-expression group $(p>0.05)$. In NSE overexpression group, the number of patients in early stage GC subgroup $(n=186,86.10 \%, T 1)$ were significantly higher than that in advanced GC subgroup $(n=124,62.20 \%$ T2-T4) $(p<0.05)$. However, in NSE under-expression group, there were more patients in advanced GC subgroup $(n=72,37.70 \%)$ than in early GC subgroup $(n=30,13.80 \%)(p<0.05)$. Patients in NSE overexpression group survived longer than those in NSE under-expression group $(p<0.05)$. The level of expression of NSE significantly decreased with increase in TNM stage $(p<0.05)$. There was no significant difference in serum NSE level between GC patients and healthy control $(p>0.05)$. The results of the correlation analysis indicated that NSE levels were positively associated with GC.

Conclusion: The results obtained in this study suggest that NSE could serve as a potential biomarker for GC.
\end{abstract}

Keywords: Biomarker, Gastric cancer, Neuron-specific enolase, Overexpression, TNM staging

This is an Open Access article that uses a fund-ing model which does not charge readers or their institutions for access and distributed under the terms of the Creative Commons Attribution License (http://creativecommons.org/licenses/by/4.0) and the Budapest Open Access Initiative (http://www.budapestopenaccessinitiative.org/read), which permit unrestricted use, distribution, and reproduction in any medium, provided the original work is properly credited.

Tropical Journal of Pharmaceutical Research is indexed by Science Citation Index (SciSearch), Scopus, International Pharmaceutical Abstract, Chemical Abstracts, Embase, Index Copernicus, EBSCO, African Index Medicus, JournalSeek, Journal Citation Reports/Science Edition, Directory of Open Access Journals (DOAJ), African Journal Online, Bioline International, Open-J-Gate and Pharmacy Abstracts

\section{INTRODUCTION}

Gastric cancer (GC) is a common digestive tract cancer characterized by high morbidity and mortality. Although it can be treated if diagnosed early, the 5-year survival and overall prognosis are unsatisfactory. It is the fifth most common type of cancer in males, and the fourth most 
common cancer in females [1]. In China, mortality due to GC is highest in the north, in the Liaodong and Shandong peninsulas, Yangtze River Delta, and in the mid-western provinces along Taihang Mountain, Hexi Zoulang, and the Hexi Corridor [2]. The first-line treatment for GC entails surgery is in combination with adjuvant chemotherapy.

Enolase, also known as phosphopyruvate hydratase, is a metalloenzyme responsible for the catalytic conversion of 2-phosphoglycerate to phosphoenol pyruvate, the ninth and penultimate step in glycolysis $[3,4]$. Human enolase comprises three subunits: alpha $(\alpha)$, beta $(\beta)$, and gamma $(\gamma)$, each encoded by a separate gene. These forms can combine to form five different isoenzymes: $\alpha \alpha, \alpha \beta, \alpha \gamma, \beta \beta$, and $\gamma \gamma$. The a aor non-neural enolase (enolase 1 ) is localized in the human liver, brain, kidney, spleen, and adipose tissue; the $\beta \beta$ or muscle-specific enolase (enolase 3 ) is found in muscle, while $\mathrm{VY}$ or neuron-specific enolase (NSE) is present at high levels in neurons and neural tissues [3-5]. Enolase levels are raised in tumors derived from cells of neural crest and in patients with smallcell lung carcinoma (SCLC). Thus, the enzyme is used as a marker for SCLC $[5,6]$.

The association between levels of NSE and GC has not been fully elucidated. Studies have shown that NSE overexpression is related to reduced incidence of advanced GC, lymphnode metastasis, cancer-related mortality, recurrence, and longer cumulative survival [5]. Patients with GC overexpressing NSE usually have better prognosis, suggesting that NSE could serve as a potential biomarker for GC [7]. The NSE levels are also raised in neuroblastoma and islet cell tumors. Levels of NSE are proportional to tumor mass and metabolic activity, and are associated with poor prognosis. Therefore, a decrease in NSE level is indicative of a decrease in tumor mass [4]. Studies on NSE as a tumor marker have focused on patients with SCLC or neuroblastoma. As a tumor marker, neuronspecific enolase (NSE) accounts not only for tumor invasiveness, but also for the prognosis of cancer. Reports have shown that its level is increased in $35 \%$ of patients with nonneuroendocrine tumors such as non-small cell lung carcinoma (NSCLC), breast cancer, lymphoma, and multiple myeloma [8]. Neuronspecific enolase (NSE) level is reportedly associated with SCLC. However, its association with the prognosis of GC is unclear [9].

The aim of this study was to investigate the potential of NSE as a biomarker for GC.

\section{EXPERIMENTAL}

\section{Materials}

Rabbit anti-NSE monoclonal antibody was obtained from Abcam (USA); 3, 3'diaminobenzidine (DAB) was purchased from Santa Cruz Biotechnology (USA), and Ultra V Block solution was a product of Lab Vision Corporation (USA). Bicinchoninic acid (BCA) protein assay kit was purchased from Bio-Rad (USA); enhanced chemiluminescence kit was obtained from Boster Biological Technology (USA), while ELISA kit was a product of $R$ and $D$ Systems (USA).

\section{Patients and tissue samples}

Gastric cancer (GC) patients ( $n=412)$ who underwent gastrectomy were recruited over a 3year period for this study. The clinicopathological data obtained from their medical records were age, sex, histological type, depth, tumor invasion, lymph node metastasis, and distant metastasis. The patients were followed up for four years and the outcomes were assessed. Patients who did not attend follow-up visits and those who died for reasons other than GC were excluded from the study. The study protocol was approved by the Institutional Research Ethics Committee of Jining First People's Hospital of Shandong Province (No. Jining/2010/43-120). The study was carried out in accordance with International Ethical Guidelines for Health-Related Research Involving Humans prepared by the International Organization of Medical Sciences in collaboration with World Health Organization (WHO) [10]. The patients and their family members signed written informed consent. Gastric cancer was diagnosed via upper gastrointestinal endoscopy/biopsy, but in few cases diagnosis was done via chromoendoscopy with indigo dye, magnifying endoscopy, and virtual endoscopy using multidetector-row computed tomography (CT).

\section{Microarray analysis}

Biopsies (about $2.3 \mathrm{~mm}$ in diameter) obtained from patients were fixed in formalin, embedded in paraffin, and analyzed using a Trephine apparatus. A sample from the area adjacent to invasion was also obtained and the tissue microarray blocks were subjected to analysis.

\section{Immunohistochemistry}

Tissue sections ( $3 \mu \mathrm{m}$ thickness) were subjected to immunohistochemistry (IHC). The sections were deparaffinized, rehydrated, and incubated in $3 \% \mathrm{H} 2 \mathrm{O} 2$ for $10 \mathrm{~min}$ to reduce non-specific 
background staining. Then the tissue samples were agitated for $15 \mathrm{~min}$ in $10 \mathrm{mM}$ citrate buffer $(\mathrm{pH} 6.0)$ in a microwave oven. In order to further reduce background staining, the sections were incubated for $10 \mathrm{~min}$ at room temperature in Ultra $\mathrm{V}$ Block solution. This was followed by the addition of rabbit anti-NSE monoclonal antibody (1 : 250) and incubation for $2 \mathrm{~h}$ at room temperature. Antibody binding was determined using Ultra-vision LP System according to the manufacturer's instructions. The sections were developed using $\mathrm{DAB}$, and counterstained with hematoxylin. Neuron-specific enolase (NSE) expression was scored based on clinicopathological data. Staining was scored as percentage of cells with NSE-positive cytoplasm. Zero (0) score was considered negative for NSE, and scores of $1+$ to $4+$ were taken for NSE overexpression.

\section{Western blotting}

The level of expression of NSE in fresh frozen tumor samples was determined using Western blotting. Biopsies were trypsinized with $0.05 \%$ trypsin and the resultant cell suspension was washed with phosphate-buffered saline (PBS) and lysed with ice-cold radio-immunoprecipitation assay (RIPA) buffer containing protease inhibitor. The lysate was centrifuged at $12,000 \mathrm{rpm}$ for 10 min at $4{ }^{\circ} \mathrm{C}$, and the protein concentration of the supernatant was determined using BCA assay kit. A portion of total cell protein $(30 \mu \mathrm{g})$ from each sample was separated on $20 \%$ sodium dodecyl sulphate (SDS)-polyacrylamide gel electrophoresis and transferred to a fixed polyvinylidene fluoride membrane at $110 \mathrm{~V}$ and $90^{\circ} \mathrm{C}$ for $120 \mathrm{~min}$. Subsequently, non-fat milk powder (3\%) in Tris-buffered saline containing $0.2 \%$ Tween-20 (TBS-T) was added with gentle shaking at $37^{\circ} \mathrm{C}$ and incubated to block nonspecific binding of the blot. Incubation of the blots was performed overnight at $3^{\circ} \mathrm{C}$ with primary antibodies of NSE and $\beta$-actin, each at a dilution of 1 to 10,000 . Then, the membrane was washed thrice with TBS-T and further incubated with horseradish peroxidase-conjugated goat anti-rabbit lgG secondary antibody for $1.5 \mathrm{~h}$ at room temperature. The blot was developed using an X-ray film. Grayscale analysis of the bands was performed using Bio-rad gel imaging system Respective protein expression levels were normalized to that of $\beta$-actin which was used as a standard.

\section{Determination of serum levels of NSE}

Peripheral venous blood $(5 \mathrm{~mL})$ was collected from 98 patients (38 healthy control and 60 patients with GC) via venipuncture, and centrifuged at $3000 \mathrm{rpm}$ for $10 \mathrm{~min}$ to obtain serum which was stored at $-70{ }^{\circ} \mathrm{C}$. The level of NSE in the serum was determined using ELISA kit. Absorbance of sample was read at $400 \mathrm{~nm}$ in a microplate reader.

\section{Statistical analysis}

Data are expressed as mean \pm SD. Statistical analysis was performed using SPSS (19.0). Groups were compared using Student's t-test. Survival was analyzed using Kaplan-Meier analysis. Statistical significance was assumed at $p<0.05$.

\section{RESULTS}

\section{Patients clinicopathological data}

The mean age of the patients, female to male ratio, and average tumor size were $61.2 \pm 10.8$ years, $1: 2$ and5.1 $\pm 2.9 \mathrm{~cm}$, respectively. The TNM stages of GC patients were as follows: stage I = 266 patients $(64.50 \%)$; stage $\mathrm{II}=60$ patients $(14.50 \%)$; stage $\mathrm{III}=83$ patients $(20.10$ $\%)$; and stage IV $=3$ patients $(0.70 \%)$. The patients underwent subtotal or total resection or proximal gastrectomy. Subtotal resection was performed on 298 patients, total resection involved 84 patients, while proximal gastrectomy was done on 30 patients. The mean follow-up time was $52 \pm 3$ months. Recurrence was observed in 58 of the 412 patients (14.07\%), and the number of cancer-related mortality was $54(13.10 \%)$. The results of IHC showed that NSE was differentially expressed in the cytoplasm of GC cells. The level of expression of NSE was measured on a scale of 0 (minimum) to 4 (maximum). A total of 102 patients scored 0 , 100 patients scored 1, a score of 2 was obtained in 92 patients; 85 patients scored3, while 33 patients scored 4. The levels of expression of NSE were further categorized into two groups: overexpression and under-expression groups. The overexpression group comprised patients that scored $1-4(n=310)$, while the underexpression group consisted of patients that scored $0(n=102)$. These results are shown in Table 1 and Figure 1.

\section{Tumor invasion, lymph node metastasis, and recurrence}

Histological changes in biopsies of patients in the overexpression group were not significantly different from those of patients in underexpression group $(p>0.05)$. The patients were subsequently classified into two GC subgroups: early (T1) and advanced (T2 - T4) subgroups. 
Table 1: Clinicopathological data of patients

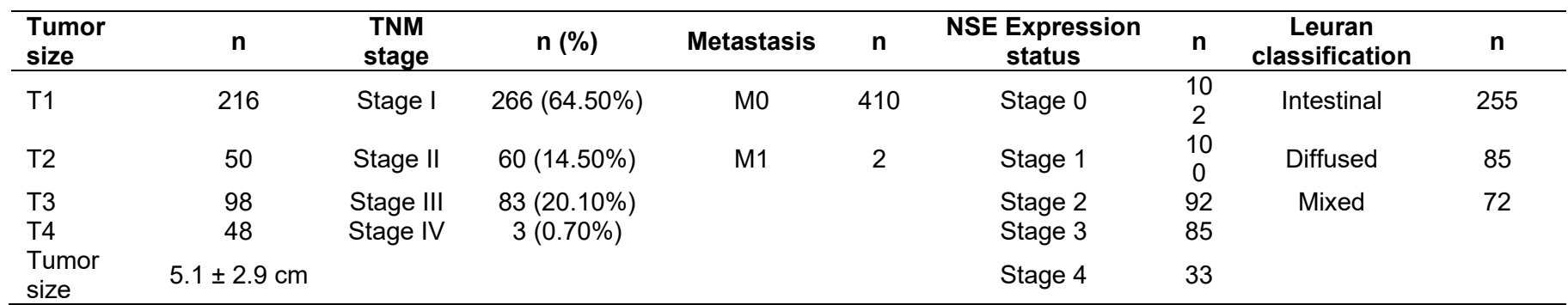
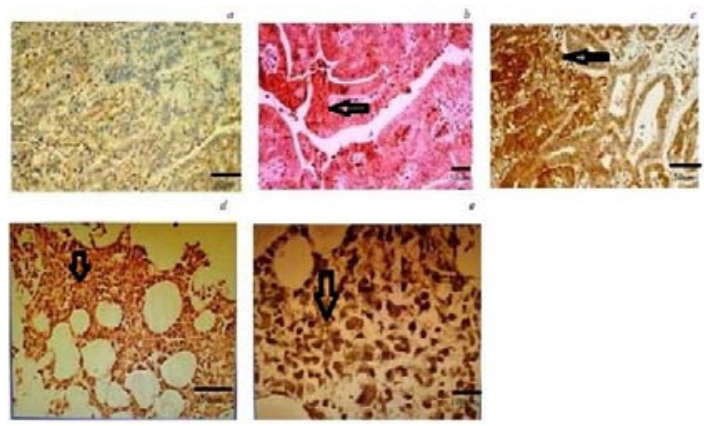

Figure 1: Histopathological features of IHC. Arrows indicate the level of reactivity

In NSE overexpression group, the number of patients in early stage GC subgroup ( $\mathrm{n}=$ 186, $86.10 \%$, T1) were significantly higher than that in advanced $\mathrm{GC}$ subgroup ( $\mathrm{n}=$ $124,62.20 \%$ T2- T4) ( $p<0.05)$. however, in NSE under-expression group, there were more patients in advanced GC subgroup ( $\mathrm{n}$ $=72,37.70 \%)$ than in early $\mathrm{GC}$ subgroup $(\mathrm{n}$ $=30,13.80 \%)(p<0.05$; table 2$)$.

The overexpression group had a significantly lower mortality, higher survival, lower tumor recurrence level and lower percentage of cancer-related morality and survival than the under-expression group (table 2). Recurrence was significantly higher in NSE under-expression group than in NSE overexpression group $(p<0.05)$ (table 2).

\section{Survival time of patients}

As shown in figure 2, mean survival time was significantly higher in the overexpression group (87 \pm 1.8 months) than in the under-expression group $(71 \pm 2.8$ months $)(p<0.05)$.

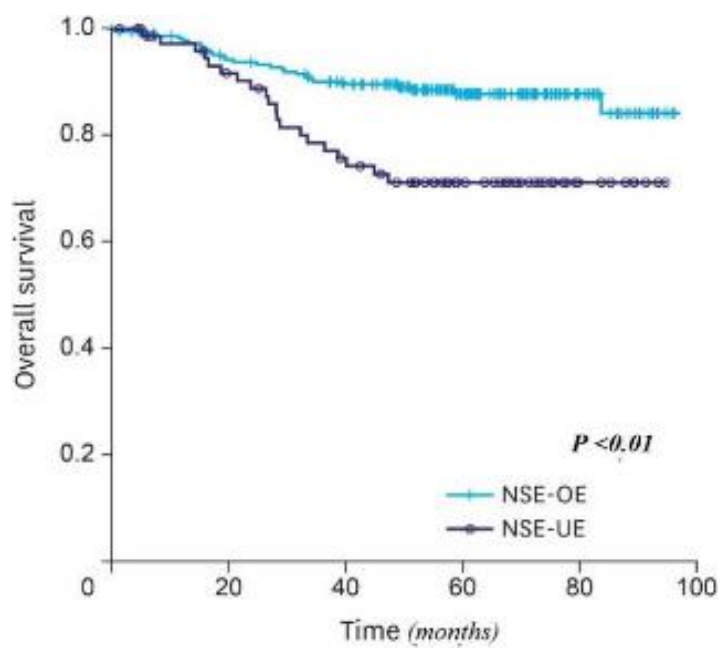

Figure 2: Kaplan-Meier analysis

Table 2: Clinicopathological parameters as evaluated by IHC

\begin{tabular}{|c|c|c|c|c|}
\hline Category & $\mathbf{n}$ & NSE overexpression & NSE under-expression & $p$ \\
\hline Tumor invasion & & & & $<0.01$ \\
\hline Early GC & 216 & $186(86.10 \%)$ & $30(13.80 \%)$ & \\
\hline Advanced GC & 196 & $124(62.20 \%)$ & $72(37.70 \%)$ & \\
\hline TNM Stage & & & & $<0.01$ \\
\hline T1 & 216 & $190(88.00 \%)$ & $26(12.00 \%)$ & \\
\hline $\mathrm{T} 2$ & 50 & $40(80.00 \%)$ & $10(20.00 \%)$ & \\
\hline T3-T4 & 146 & $80(54.70 \%)$ & $66(45.30 \%)$ & \\
\hline Cancer-related mortality & & & & $<0.01$ \\
\hline Absent & 327 & $300(91.70 \%)$ & $27(8.20 \%)$ & \\
\hline Present & 85 & $10(11.80 \%)$ & $75(88.20 \%)$ & \\
\hline Recurrence & & & & $<0.01$ \\
\hline Absent & 326 & $300(91.60 \%)$ & $26(8.40 \%)$ & \\
\hline Present & 86 & $10(11.70 \%)$ & $76(88.30 \%)$ & \\
\hline
\end{tabular}




\section{NSE level-based TNM stage}

The level of expression of NSE was significantly reduced with increased TNM stage ( $p<0.05$; figure 3$)$.

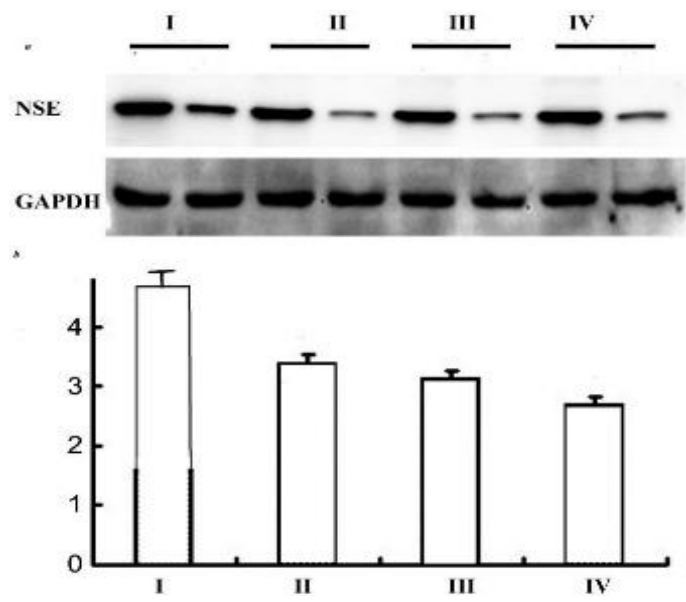

Figure 3: Level of expression of NSE, as measured using western blotting

\section{Serum level of NSE}

There was no significant difference in serum NSE level of patients with GC and healthy control ( $p>0.05$; figure 4 ).
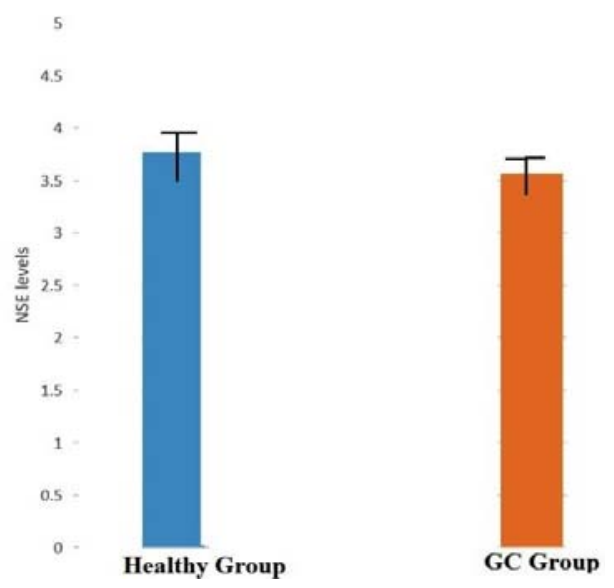

Figure 4: Serum levels of NSE in GC patients and healthy control

\section{Other factors affecting overall survival}

The results of multivariate Cox analysis showed that age, sex, history of smoking, and pathology other than tumor did not affect overall survival ( $p$ $>0.05$, RR $<3.05$ ), but tumors of other origins with metastasis did $(p>0.05, \mathrm{RR}<5.1)$.

\section{DISCUSSION}

Gastric cancer (GC) is the fourth most common malignant tumor, and the second leading cause of cancer-related deaths worldwide [1]. The incidence of GC has increased on a global scale over the last few decades [1]. The incidence is highest in Southern America, Eastern Asia and Eastern Europe, and lowest in Northern America and Africa [1]. The pathogenesis of $\mathrm{GC}$ is a complex process involving several genes and regulatory pathways. The association between levels of NSE and GC has not been fully elucidated. Studies have shown that NSE overexpression is related to reduced incidence of advanced GC, lymph node metastasis, cancerrelated mortality, recurrence, and longer cumulative survival [5]. This study investigated the potential of NSE as a biomarker for GC. The overexpression of NSE was related to lower TNM stage, reduced cancer-related mortality and longer survival. However, serum levels of NSE did not significantly differ between patients with GC and healthy control.

Over the years, research effort has focused on the identification of biomarkers predictive of survival and recurrence in patients with GC $[11,12]$. However, no such biomarker has been discovered to date $[12,13]$. Human epidermal growth factor 2 (HER2) has been reported to have potential prognostic value for GC, but its sensitivity and specificity are not significant enough for clinical application $[12,13]$. The use of anti-HER monoclonal antibody in combination with chemotherapy has been shown to be effective against GC, when compared with other treatment strategies [15-18].

Table 3: Overall survival according to Cox multivariate analysis

\begin{tabular}{lllc}
\hline Variable & & HR & $\boldsymbol{p}$ \\
\hline Sex & Male & 1.20 & $>0.05$ \\
Age & $<50$ years & 1.90 & $>0.05$ \\
Smoking history & Nil & 0.90 & $>0.05$ \\
Pathology & Any inflammatory reaction & 2.70 & $>0.05$ \\
Other tumors & Non-adenocarcinoma & 5.10 & $<0.05$ \\
Chemotherapy lines & $\geq 2$ & 0.30 & $>0.05$ \\
\hline
\end{tabular}


The levels of NSE are predictive of stage IV lung cancer. Indeed, NSE is an important marker in patients with neuronal damage as seen in cerebral and cerebellar infarction, brain hemorrhage, epileptic disorders, and brain trauma. Neuron-specific enolase (NSE) leaks from neurons during necrosis [19,20].

Studies on the levels of NSE in patients with GC and healthy control are scanty. In a previous study, it was reported that NSE overexpression could serve as a prognostic tool for $\mathrm{GC}$, since it was correlated with lower TNM stage, lymph node metastasis, and longer survival [7]. In that study, there was no significant difference in preoperative NSE level in serum of patients with GC, relative to healthy control. It has been reported that NSE levels are correlated with NSE expression in tissue specimens of patients with prostate cancer (PC) [21]. In a previous study, it was reported that elevated levels of NSE are associated with poor prognosis in patients with PC [22]. Pretreatment NSE level has been shown to be independently associated with failure-free survival in patients with localized PC [23]. It has also been reported that NSE levels are correlated with survival and constitute an independent risk factor for the prognosis of patients with lung cancer [24].

The correlation of NSE levels with infarction volume, severity of neurological dysfunction, location of infarction, prognosis, and other indicators has been reported [25]. The results of this study indicate that NSE levels are positively associated with GC.

\section{Limitations of the study}

The likely limitations of this study are: (1) failure to use NSE level as an independent prognostic factor in multivariate analysis; (2) short follow-up period; and (3) failure to screen patients used as healthy control for systemic diseases before inclusion in the study.

\section{CONCLUSION}

The results obtained in this study suggest that NSE could serve as a potential biomarker for GC.

\section{DECLARATIONS}

\section{Conflict of interest}

No conflict of interest is associated with this work.

\section{Contribution of authors}

We declare that this work was done by the authors named in this article and all liabilities pertaining to claims relating to the content of this article will be borne by the authors.

\section{Open Access}

This is an Open Access article that uses a funding model which does not charge readers or their institutions for access and distributed under the terms of the Creative Commons Attribution License (http://creativecommons.org/licenses/by/ 4.0) and the Budapest Open Access Initiative (http://www.budapestopenaccessinitiative.org/rea d), which permit unrestricted use, distribution, and reproduction in any medium, provided the original work is properly credited.

\section{REFERENCES}

1. Torre LA, Bray F, Siegel RL, Ferlay J, Lortet-Tieulent J, Jemal A. Global cancer statistics, 2012.CA Cancer J Clin 2015; 65: 87-108.

2. Xiaodong Zhu, Jin Li. Gastric carcinoma in China: Current status and future perspectives (Review). Oncol Lett 2010 ; 1(3) :407-412.

3. Pinson P, Joos G, Watripont $P$, Brusselle $G$, Pauwels $R$. Serum neuron-specific enolase as a tumor marker in the diagnosis and follow-up of small-cell lung cancer. Respiration1997; 64: 102-107.

4. Cooper EH. Neuron-specific enolase. Int $\mathrm{J}$ Biol Markers1994; 9: 205-210.

5. Kaiser E, Kuzmits R, Pregant P, Burghuber O, Worofka W. Clinical biochemistry of neuron specific enolase. Clin Chim Acta1989; 183: 13-31.

6. Jørgensen LG, Osterlind $K$, Hansen $H H$, Cooper $E H$. Serum neuron-specific enolase (S-NSE) in progressive small-cell lung cancer (SCLC). Br J Cancer1994; 70: 759-761.

7. Massarelli G, Onida GA, Piras MA, Marras V, Mura A, Tanda F. Neuron-specific enolase (gamma enolase, gamma-gamma dimer) expression in Hodgkin disease and large cell lymphomas. Anticancer Res1999; 19: 3933-3938.

8. Park T, Lee YJ, Jeong SH, Choi SK, Jung EJ, Ju YT, Jeong CY, Park M, Hah YS, Yoo J. Overexpression of neuron-specific enolase as a prognostic factor in patients with gastric cancer. J Gastric Cancer 2017; 17(3): 228-236.

9. Kimura M, Tsuda $H$, Morita $D$, Ichikura $T$, Ogata $S$, Aida S. A proposal for diagnostically meaningful criteria to classify increased epidermal growth factor receptor and c erbB-2 gene copy numbers in gastric carcinoma, based on correlation of fluorescence in situ hybridization and immunohistochemical measurements. Virchows Arch 2004; 445: 255-262.

Trop J Pharm Res, March 2020; 19(3): 510 
10. Macrae DJ. The Council for International Organizations and Medical Sciences (CIOMS) guidelines on ethics of clinical trials. Proc Am Thorac Soc 2007; 4(2): 176-178.

11. Cho HJ, Baek KE, Park SM, Kim IK, Choi YL, Cho HJ, Nam IK, Hwang EM, Park JY, Han JY et al. RhoGDI2 expression is associated with tumor growth and malignant progression of gastric cancer. Clin Cancer Res 2009; 15: 2612-2619.

12. Kim MA, Lee HS, Lee HE, Jeon YK, Yang HK, Kim WH. EGFR in gastric carcinomas: Prognostic significance of protein overexpression and high gene copy number. Histopathology $2008 ; 52: 738-746$.

13. Cho JY. Molecular diagnosis for personalized target therapy in gastric cancer. J Gastric Cancer $2013 ; 13$ :129-135.

14. Bang YJ, Van Cutsem E, Feyereislova A, Chung HC, Shen L, Sawaki A, Lordick F, Ohtsu A, Omuro $Y$, Satoh $T$ et al. Trastuzumab in combination with chemotherapy versus chemotherapy alone for treatment of HER2positive advanced gastric or gastro-oesophageal junction cancer (ToGA): A phase 3, open-label, randomised controlled trial. Lancet 2010; 376: 687-697.

15. Corso G, Pedrazzani C, Marrelli D, Pascale V, Pinto E, Roviello $F$. Correlation of microsatellite instability at multiple loci with long-term survival in advanced gastric carcinoma. Arch Surg2009; 144: 722-727.

16. Park YS, Jin MY, Kim YJ, Yook JH, Kim BS, Jang SJ. The global histone modification pattern correlates with cancer recurrence and overall survival in gastric adenocarcinoma. Ann Surg Oncol2008; 15: 1968-1976.

17. Wu WK, Cho CH, Lee CW, Fan D, Wu K, Yu J, Sung JJl. Dysregulation of cellular signaling in gastric cancer. Cancer Lett 2010; 295: 144-153.
18. Xiangming C, Hokita S, Natsugoe S, Tanabe G, Baba M, Takao S, Kuroshima K, Aikou T. p21 expression is a prognostic factor in patients with p53-negative gastric cancer. Cancer Lett2000; 148: 181-188.

19. Yu D, Du K, Liu T, Chen G. Prognostic value of tumor markers, NSE, CA125 and SCC, in operable NSCLC patients. Int J Mol Sci 2013; 14: 11145-11156.

20. Dong Y, Zheng X, Yang Z, Sun M, Zhang G, An X, Pan L, Zhang $S$. Serum carcinoembryonic antigen, neuronspecific enolase as biomarkers for diagnosis of nonsmall cell lung cancer. J Cancer Res Ther 2016; 12: 3436.

21. Kamiya, N, Suzuki, H, Kawamura, K. Neuroendocrine differentiation in stage D2 prostate cancers. Int J Urol 2008; 15(5): 423-428.

22. Berruti, A, Dogliotti, L, Mosca, A. Circulating neuroendocrine markers in patients with prostate carcinoma. Cancer 2000; 88(11): 2590-2597.

23. Lilleby, W, Paus, E, Skovlund, E, Fosså, SD. Prognostic value of neuroendocrine serum markers and PSA in irradiated patients with $\mathrm{pNO}$ localized prostate cancer. Prostate 2001; 46(2): 126-133.

24. Xue F, Zhu L, Wang $L$, Wang $Q$. Serum neuron specific enolase levels correlate with patient prognosis for advanced lung cancer. Int J Clin Exp Med 2015; 8(6): 9498-9504.

25. Patout $M$, Salaün $M$, Brunel V, Bota S, Cauliez B, Thiberville L. Diagnostic and prognostic value of serum procalcitonin concentration in primary lung cancer. Clin Biochem 2014; 47: 263-267. 